\title{
Convective heat transfer from a cylinder mounted on a plane wall
}

\author{
by Tommaso Astarita, Rosaria Giordano and Giovanni Maria Carlomagno
}

\section{DIAS - University of Naples "Federico II", Naples, Italy}

The purpose of this work is an accurate analysis of the convective heat transfer caused by the wake of a finite cylinder mounted on a plane wall, by means of the infrared (IR) thermography applied to the steady state heated-thin-foil technique.

The used experimental set-up (see figure 1 ) is composed of an aspirated subsonic open circuit wind tunnel which has a low turbulence intensity level $(0.1 \%)$ and a rectangular test section of $300 \times 400 \mathrm{~mm}^{2}$. Four different cylinder have been used with a diameter of $26 \mathrm{~mm}$ and different lengths giving the aspect ratios: $A R=1,2,4,8$. The free-stream velocity is measured with a differential pressure transducer and the Reynolds number investigated, based on the cylinder diameter, are 8000, 16000 and 32000.

The wall on which heat transfer measurements are performed is constituted of a printed circuit board $\left(300 \times 600 \mathrm{~mm}^{2}\right.$ and designed so as to ensure a constant heat flux over the wall), this board starting immediately downstream of the tunnel throat. The circuit copper tracks are $5 \mu \mathrm{m}$ thick, $1.8 \mathrm{~mm}$ wide and located at $2 \mathrm{~mm}$ pitch, the overall thickness of the board being $0.5 \mathrm{~mm}$. The surface of the printed circuit board which is not exposed to flow is thermally insulated. A stabilized DC power supply provides the electric current to the circuit and, by measuring voltage drop and current across the board, it is possible to compute the dissipated power and, therefore, the heat flux. The surface viewed by the IR camera is coated with a thin layer of opaque paint, which has a total emissivity coefficient $\varepsilon=0.95$ in the wavelength of interest.

The infrared thermographic system used is the Agema Thermovision 900LW. Images are scanned in the 8-12 $\mu \mathrm{m}$ infrared band with a mercury-cadmium-tellurium ( $\mathrm{Hg}-\mathrm{Cd}-\mathrm{Te})$ detector, which has a thermal sensitivity of $70 \mathrm{mK}$ at room temperature. Each image is recorded as a $136 \times 272$ pixels/frame at 12 bits (4096 levels) and, to reduce noise, is time-averaged (over 32 frames) and low-pass filtered.

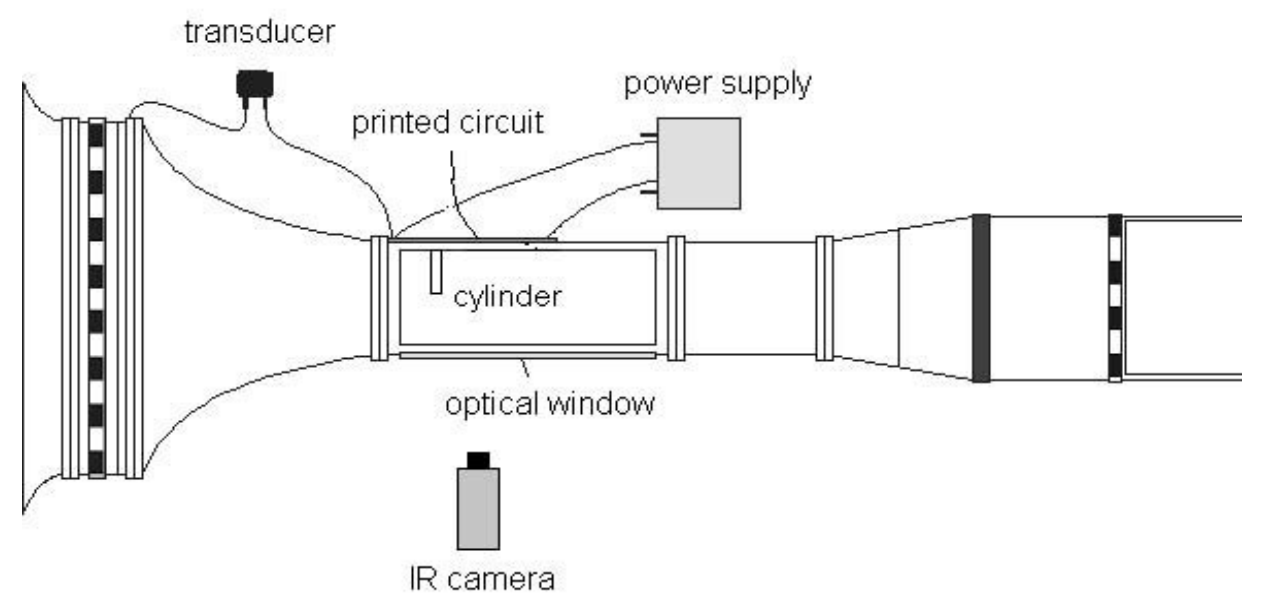

Fig. 1. Sketch of the experimental apparatus

In figure 2 the wall mean temperature maps are reported for $A R=2$ and the three Reynolds numbers investigated. The average is computed on 180 images.

Experimental results will be presented in terms of Nusselt number maps and the comparison of the convective heat transfer coefficient for different Reynolds number as well as for different aspect ratios will be shown. 
http://dx.doi.org/10.21611/qirt.2008.07_02_11

Q IrkT2008

9th International Conference on Quantitative InfraRed Thermography
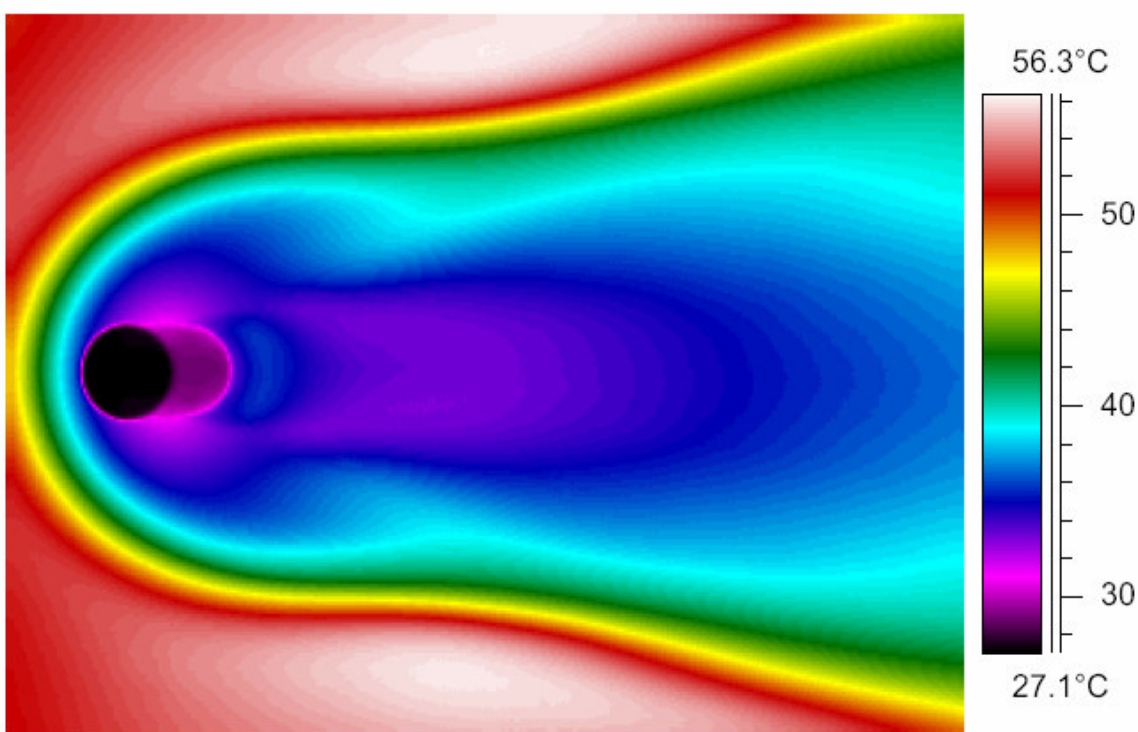

a)
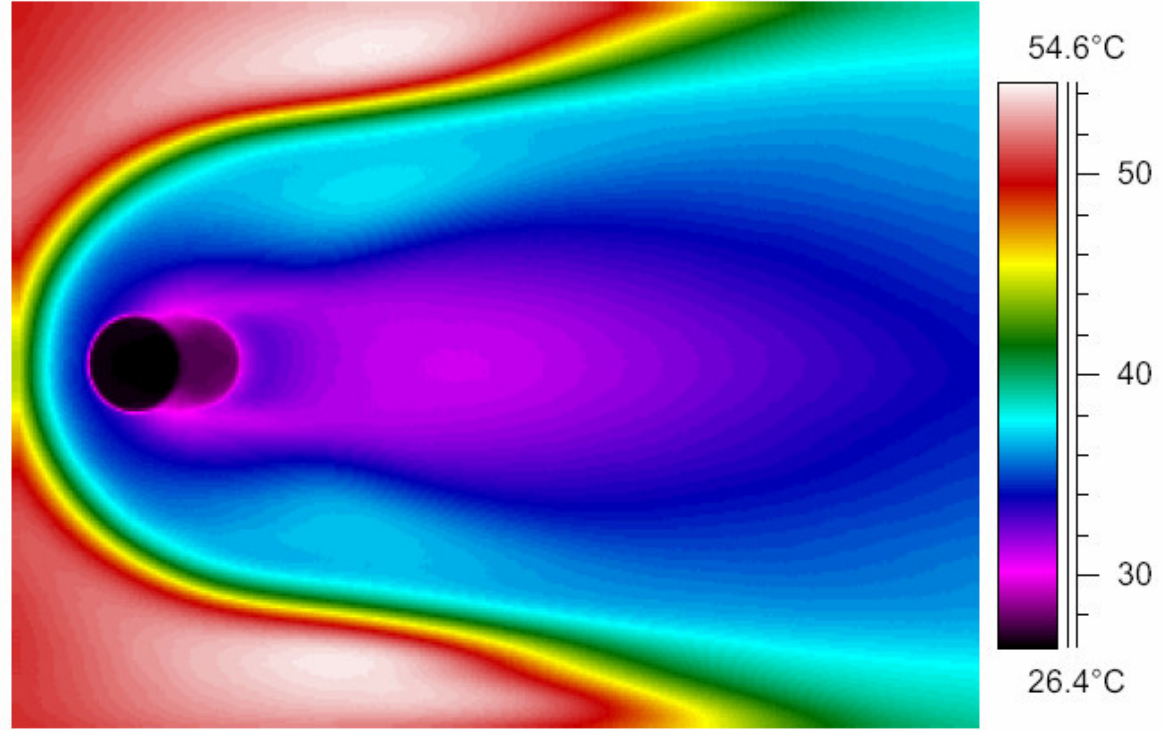

$26.4^{\circ} \mathrm{C}$

b)

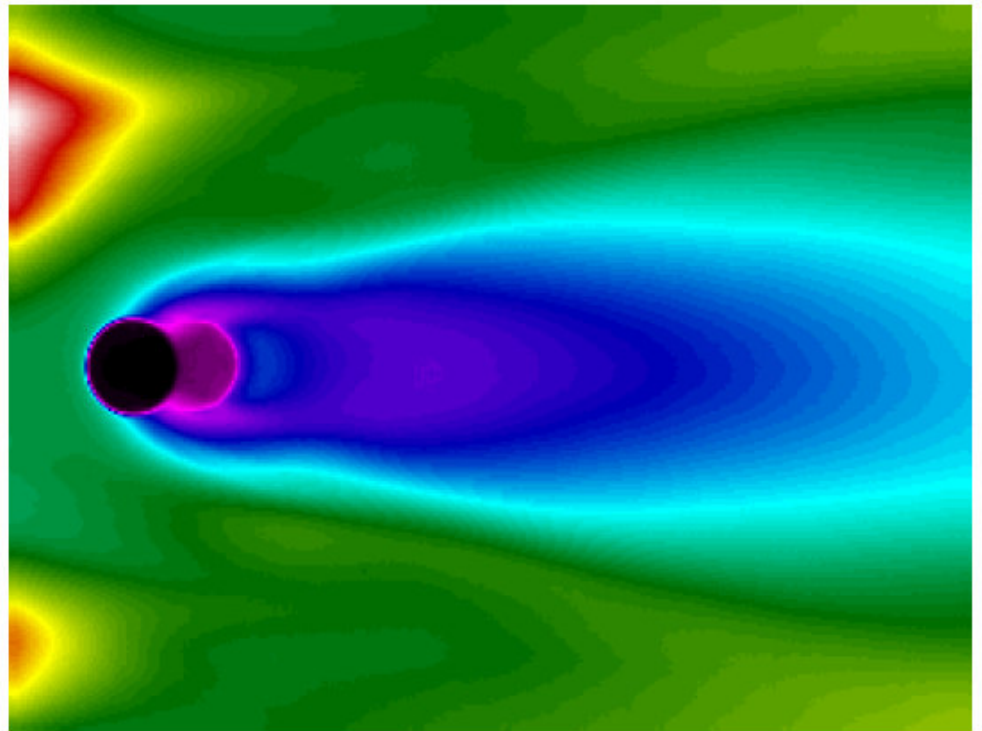

$53.8^{\circ} \mathrm{C}$

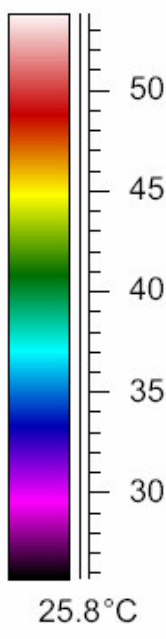

Fig.2. Mean temperature map for $A R=2$ and: a) $R e=8000$; b) $R e=16000$; c) $R e=32000$ 